\title{
Interdisciplinaridade, meio ambiente e desenvolvimento: limitações e desafios da/à sociedade brasileira
}

\section{Interdisciplinarity, the environment and development: limitations and challenges posed by and to brazilian society}

\author{
Carlos Augusto de Figueiredo MONTEIRO*
}

\section{RESUMO}

\begin{abstract}
A discussão acerca da interdisciplinaridade, a partir da perspectiva da questão ambiental, é aqui desenvolvida sob a abordagem da experiência acadêmica e em consultorias do autor no campo da ciência geográfica. O texto evoca a evolução da análise geográfica sobre a relação sociedade-natureza para, evidenciando o contexto científico, explicitar limitações e desafios da construção da interdisciplinaridade. Palavras-chave: interdisciplinaridade, questão ambiental, limitações, desafios, geografia.
\end{abstract}

\begin{abstract}
The discussion on interdisciplinarity, from the environmental perspective, is developed here under the light of the author's academic experience and consulting work developed in geographic science. The text evokes the evolution of geographical analysis on the society-nature relationship, highlighting the scientific context, providing clarification on the limitations and challenges posed by the construction of interdisciplinarity. Key-words: interdisciplinarity, environmental issue, limitations, challenges, geography.
\end{abstract}

Esta universidade convidou-me, em 1999, para participar do Seminário Internacional realizado pelo Doutorado Interdisciplinar em Meio Ambiente e Desenvolvimento, o que honrou-me sobremaneira. Naquela época já me encontrava na condição de aposentado como Professor Titular da Universidade de São Paulo, mas não assumindo o apodo de "inativo" posto que estudando, fazendo reflexões autocríticas sobre minha produção geográfica, comparecendo a fóruns geográficos, e proferindo, eventualmente, palestras em diferentes instituições.
Recordo-me que naquele evento preocupei-me com a pauta "conceitual" básica para o que me serviu de apoio aquela obra que foi, sem dúvida, um marco na abordagem dos diferentes modos de "disciplinaridades", visando à adequação das universidades aos novos tempos. Aquela famosa coletânea de abordagens feitas por estudiosos das mais elevadas credenciais acadêmicas, rotulada "Interdisciplinarity - Problems of Teaching and Research in Universities" resultado de um Seminário realizado na Universidade de Nice (França) entre 07 e 12 de setembro de $1970 .^{2}$

\footnotetext{
* Doutor em Geografia. Professor Emérito da Universidade de São Paulo.

1 Na realidade, essa obra cuja referência encontra-se no final deste, foi editada em inglês, francês e alemão. Adquiri um exemplar em inglês em Aberystwich, País de Gales, (21.01.1974) e outro em francês - doado ao Departamento de Geografia da FFLCH/USP - em Florença, Itália - nessa mesma viagem.

2 Recordo que, naquele primeiro seminário, errei ao apontar a Universidade de Bordeaux, em vez de Nice.
} 
MONTEIRO, C. A. de F. Interdisciplinaridade, meio ambiente e desenvolvimento...

Naquele então, mobilizei alguns poucos exemplos ilustrativos das concepções básicas do espectro conceitual das disciplinaridades. No presente encontro - quero adverti-vos de que venho trazer um depoimento de uma atuação já passada. Não um passado remoto, mas, assim mesmo, passado. Na minha carreira acadêmica pude fruir, paralelamente, de uma significativa experiência junto a equipes interdisciplinares de planejamento, tanto em instituições públicas (Secretaria de Planejamento, Ciência e Tecnologia do Estado da Bahia) quanto privadas (Arquiteto Joaquim Guedes \& Associados, Arquiteto Paisagista Rosa Kliass). Essa prática foi significativa entre 1970-1985, declinante até 1990, quando se extinguiu completamente.

Assim sendo, meu depoimento apóia-se tanto no nível da prática acadêmica, intra-universitária, quanto no da aplicação prática no planejamento territorial. Atenho-me a seguir o que o tema propõe para este encontro - "limitações" e "desafios" à prática da "interdisciplinaridade". Não diria na "sociedade moderna" mas, prudente e honestamente restrito ao caso brasileiro, limite da minha vivência.

Gostaria de relembrar apenas que, das referências conceituais básicas, devemos reter que, no que concerne à questão ambiental, o relacionamento das diferentes disciplinas é expresso por uma postura axiomática comum, multinivelada e de múltiplas metas, revestindo-se de um caráter "composito" desde que impelida por particulares forças propulsoras que desafiam a dignidade e sobrevivência do Homem (teleológico, normativo e proposital) (JANTSCH, 1972).

Parece evidente que, diante de tão complexa e altruísta meta, devam antepor-se várias limitações e desafios a serem superados. Sem qualquer pretensão de atingir todo o conjunto, trago a consideração da presente assembléia alguns deles.

\section{Algumas limitações}

Tudo parece indicar que, em determinados momentos, deparamo-nos com problemas novos para os quais não dispomos de tradição em enfrentá-los, exigindo que, para encontrar soluções, torne-se imprescindível promover mudanças substanciais de procedimentos, hábitos, atitudes, tarefa nem sempre fácil posto que inerciamente há aquela tendência em cristalizar o status quo.

No caso da prática de interdisciplinaridade, condição essencial para fazer face à questão ambiental, parece- me que o ponto de partida está na associação dos problemas de formação acadêmica e institucionalização profissional.

A organização vigente em nossas universidades, estruturadas desde o início do século passado em torno de departamentos estanques, alia desvantagens funcionais administrativas e estruturas curriculares rígidas. Embora, em alguns casos, já existam consideração de núcleos básicos aos quais se juntariam algumas feições de livre escolha dos graduandos, ainda se está longe daquela flexibilidade curricular que satisfaça a liberdade do estudante capaz de direcioná-lo a perspectivas (de investigação e profissionalização) novas que parecem ampliar-se a cada dia nesses tempos ditos pós-modernos.

Felizmente este inconveniente já vem merecendo um corretivo que, embora não totalmente sanado, já representa um grande passo em direção à prática da interdisciplinaridade. E disso não preciso mobilizar qualquer amostra além do que foi implantado aqui nesta universidade Federal do Paraná, nessa bem-sucedida proposta de Doutorado Interdisciplinar. Constata-se que enquanto não foi possível aplicá-la na graduação, isso pode ser conduzido ao nível da Pós-Graduação.

Em contrapartida, encontramos entre nós preocupações de interdisciplinaridade na educação básica-fundamental (JAPIASSU, 1976) e até mesmo na Geografia (ROKENBACH e CALVENTE, 1991).

As algemas da rigidez curricular de uma graduação junta-se à camisa-de-força do corporativismo profissional capaz de gerar procedimentos altamente estranhos, às vezes inconcebíveis. Não há dúvidas de que o "espírito de corpo" tem aspectos altamente positivos, no que diz respeito solidariedade interna de um conjunto profissional. $\mathrm{O}$ problema é que a exacerbação do espírito de corpo tornese a uma externa competição. Alguns exemplos colhidos de minha experiência podem ser aqui apontados:

No final dos anos setenta, quando à frente do Laboratório de Climatologia do então Instituto de Geografia da USP - o núcleo de trabalho de pesquisa dos pesquisadores em climatologia e estágio dos orientandos na Pós-Graduação -, uma das alunas estagiárias conseguiu um trabalho no Instituto Biológico. Estava atuando numa equipe de pesquisa, investigando sobre o chamado "mal de sigatoca" que danificava os bananais da baixada da Ribeira do Iguape. Naquele conjunto, ela era o elemento encarregado de analisar e interpretar os dados climatológicos. A moça corria o risco de perder o emprego, pois os engenheiros agrônomos 
MONTEIRO, C. A. de F. Interdisciplinaridade, meio ambiente e desenvolvimento...

estavam movendo uma ação contra vários pesquisadores por exercício indevido da profissão. Neste caso, se enquadravam aqueles pretensos pesquisadores que, ao contrário deles, não possuíssem carteira profissional do Crea. Naquele então muitas profissões ainda não haviam tido reconhecimento ou melhor "regulamentação" oficial. O mais espantoso no caso em foco é que a maioria dos pesquisadores a ser atingidos era aquela dos biólogos. E isso no Instituto de Biologia.

Já na atual virada dos séculos, pode-se constatar que já existem eloqüentes sinais de mudanças nessa estrita mentalidade corporativa. Para a realização do Simpósio de Climatologia Geográfica, realizado na cidade do Rio de Janeiro entre 27 de novembro e $1 .^{\circ}$ de dezembro do ano de 2000, a comissão organizadora daquele evento recebeu o mais decisivo apoio do Crea do Rio de Janeiro, de várias maneiras, inclusive no espaço físico, desde que os auditórios da sede e o corpo de funcionários do Crea prestou a mais eficiente atuação naquele evento. E durante aquele contacto, os geógrafos presentes puderam constatar que o Crea-RJ estava efetivamente ligado à questão ambiental, sob vários aspectos. Inclusive numa preciosa assistência que estava sendo dada às prefeituras do Estado do Rio de Janeiro, na solução de problemas ambientais que afligiram alguns municípios fluminenses. Além do que, o próprio Crea-RJ vinha promovendo eventos de congraçamento entre engenheiros e outros profissionais. Em suma, uma mudança sensível na eliminação daquele ranço de corporativismo medieval que afetava a instituição.

Outro depoimento, muito auspicioso, que posso incluir aqui é aquele da realização do IV Congresso da Sociedade Brasileira de Arborização Urbana - SBAU realizado em Belém do Pará, entre os dias 23 e 27 de setembro do passado ano de 2003. Fui convidado, como geógrafo, para fazer uma palestra ${ }^{3}$ sobre o problema da arborização nas cidades tropicais. Estavam ali irmanados naquele evento: engenheiros florestais, agrônomos, civis, arquitetos, urbanistas, paisagistas, sociólogos e graduados em Belas Artes. Quando uso esse termo "irmanados", isso não significa que não tenha havido discussões nas quais afloravam nítidos remanescentes corporativos (sobretudo em relação a uma pretensa liderança de arquitetos-paisagistas) mas porque realmente fiquei surpreendido pelo nítido "avanço" que está possibilitando um razoável entendimento convergente para aquele problema urbano.

\section{Sérios desafios}

Parece que na convergência para a prática da interdisciplinaridade, os maiores desafios a vencer são de caráter intradisciplinar, ou seja, aqueles obstáculos que teriam que ser superados no interior das disciplinas, per si.

No caso da Geografia, o mais grave é a superação da dicotomia "natural-social". Contrariamente ao grande legado que os fundadores da Geografia-Ciência nos deixaram, ou seja, a compreensão dos lugares pelo jogo de relações dinâmicas entre diferentes fatos da natureza e da sociedade, tem progredido uma desagregante concepção de que a Geografia, em vez de algo especial, é uma mera ciência social. A superação da antiga concepção do determinismo ambiental - certamente uma necessidade induziu a outro determinismo, mais grave ainda, do "econômico".

No caso brasileiro, a supervalorização do econômico aliada à dita "crítica radical" chegou ao ponto de conduzir a Geografia feita no Brasil a um cisma que se efetivaria em 1984, quando se tornou necessário criar um "Seminário de Geografia Física-Aplicada”, de realizações bianuais para que houvesse oportunidade de existir um fórum de debate em cujo temário se incluíssem aqueles fatos e fenômenos concernentes às funções naturais que - é necessário insistir - jamais estão desvinculadas da ação do homem como agente (antropogênese geográfica) e expressão social da "produção" dos espaços geográficos.

Para mim, é perfeitamente claro que, o pretenso "geógrafo" que é incapaz de superar essa fatalidade "dicotômica" não terá aptidão a qualquer prática interdisciplinar. Se for assim, o adepto de uma "Geografia Humana" só poderá ombrear-se com sociólogos, antropólogos e economistas, enquanto aqueles de "Geografia Física" só poderiam trocar idéias com geólogos, pedólogos, climatologistas. Separação essa que colocaria por terra qualquer pretensão à Geografia como campo especial de conhecimento, inclusive no papel de "veículo de Educação".

3 Para essa palestra preparei um texto - ilustrado com o recurso de transparências para retroprojeção - que rotulei - “Arborização de Cidades Tropicais (uma abordagem geográfica do tema no contexto da grande questão urbana da virada dos séculos XX-XXI)”. Obra ainda inédita. 
MONTEIRO, C. A. de F. Interdisciplinaridade, meio ambiente e desenvolvimento...

E o absurdo é de tal ordem que até a questão ambiental se vê afetada por essa dicotomia e seu resultante cisma. Para alguns, a noção de "ambiente" se reveste prioritariamente das componentes sociais. Até mesmo na recente tendência a revalorizar os aspectos culturais na Geografia, toma-se a cultura como resultante direta da economia e da política. Enquanto a linha de pensamento dita "humanística" procura entrosar os diferentes elementos da complexidade geográfica, a new left dos anglófonos insiste naquela postura.

Enquanto há geógrafos que, consoante as evidências crescentes da existência de sistemas de alto grau de complexidade, procuram ajustar o complexo e cada vez mais intrincado jogo de interações simultâneas da Geografia na concepção de "Geossistemas", outros insistem em que o legítimo paradigma para a análise geográfica é o legado marxista da "formação social". Aqui no Brasil, desde os anos setenta, tenho feito esforços no sentido de demonstrar que não é impossível dar congruência à análise simultânea de fatos naturais e sociais (MONTEIRO, 1978). Mais recentemente, colegas geógrafos que, embora investigando em temática sócio-econômica tal como "indústrias" admitem esta possibilidade (MAMIGONIAN, 1996).

Um segundo desafio ainda internamente ligado ao corpus da Geografia - ou da comunidade de geógrafos mas que já alcançou um certo grau de aproximação ou afastamento de outros ramos da investigação científica ou do conhecimento, seria o problema da afirmação profissional e do seu grau de prestígio junto ao poder público.

E, nesse sentido, a Geografia aqui no Brasil tem um exemplo bem ilustrativo da questão proposta. Este ano a inteligentzia do país festeja os 70 anos de fundação da Universidade de São Paulo ou, melhor dizendo, da Universidade Brasileira, já que a Universidade do Brasil, instalada no Rio de Janeiro, então capital federal, é da mesma época (1934-35). Tutelada por scholars, franceses instalaram-se nas Faculdades de Filosofia (Letras e Ciências Humanas) os cursos de Geografia e História. ${ }^{4}$ Em 1937, já na vigência do Estado Novo da Ditadura Vargas, era criado o IBGE - Instituto Brasileiro de Geografia e Estatística. O "Conselho Nacional de Geografia", incluído na estrutura daquele, começou a acolher os licenciados em Geografia pelas universidades. Enquanto essas eram os órgãos formadores de geógrafos (e professores de Geografia), o IBGE tornava-se o órgão estatal que aplicava os conhecimento geográficos junto à ação do poder público federal. Enquanto a Estatística criava "agências" por todos os municípios, para obtenção das informações básicas, a Cartografia - aliada às forças armadas - promovia a produção das cartas topográficas na imensidão do nosso território, a Geografia provia as pesquisas básicas, sobretudo aquelas necessárias à regionalização do território nacional. Um estudo hoje clássico do Geógrafo Fabio de Macedo Soares Guimarães (1942) foi publicado na Revista Brasileira de Geografia. ${ }^{5}$

Até o meado do século passado, as investigações geográficas no nosso Brasil assumiam a tarefa de revelação das feições naturais de um vasto país ainda pouco ocupado, com substancial parte do território à margem da economia, sediando "marcha para o oeste", na qual bandeirantes modernos faziam contato com desconhecidas comunidades indígenas. Produzia-se uma geografia que, embora desamparada de suporte teórico específico e modesta (ou nula) utilização da linguagem matemática para conferir-lhe o status de ciência, era promotora de estudos temáticos variados e análises regionais que, imbuída dos princípios legados pelos pais (alemães) e mentores (franceses) produziam descrições explicativas bem razoáveis. No meado do século, a política desenvolvimentista do governo Kubitschek (50 anos em 5) e sobretudo a criação de Brasília ensejou um ativamento nas análises temáticas variadíssimas (demográficas, produção agrícola etc.) e análises regionais do Centro-Oeste. Mas exatamente nessa época (meio do século), a força do capitalismo do pós-guerra (Segunda Mundial) assinalando a hegemonia norte americana firmada em Bretton Woods (1944) promoveu o deslanche do determinismo econômico. Assim, no IBGE o interesse nos estudos geográficos (temáticos e regionais) entraram em declínio enquanto eram valorizados os dados estatísticos capazes de promover a definição de microrregiões homogêneas e estudos de redes urbanas, de transportes e fluxos de mercadorias e comunicações.

4 Cursos que continuariam juntos até 1957 quando a Universidade de São Paulo houve por bem separá-los no que foi seguida, a partir daí, pelas outras universidades que já se multiplicavam pelo País.

5 "Pastiche" da American Geographical Review, a nossa RBG, era, juntamente com o Boletim Geográfico, um dos órgãos de divulgação da produção oficial da instituição, mas também acolhedora do que lhe chegava das universidades, além de transições. Fundada em 1938, teve uma edição comemorativa do cinqüentenário em 1988. Declinando progressivamente, a partir dos anos setenta, a revista publicou seu último número, em grande atraso, com a data de 1995. 
MONTEIRO, C. A. de F. Interdisciplinaridade, meio ambiente e desenvolvimento...

A visão de "regionalização" do território absorvia as variáveis econômicas, segundo propostas experimentais no início do anos sessenta, até que em 1968-69 o IBGE promove um grande fórum de debates, rotulado Confege (Conferência de Geografia) durante o qual se apregoava a necessidade urgente de adoção de técnicas de quantificação (Revolução Quantitativa) e preocupações teóricas (Revolução Teorética).

Em todos os processos de mudanças é preciso que se aponte uma data que - embora reconhecidamente simbólica - sirva de marco registrador dessa mudança. Na minha visão, acho que a edição da obra "Subsídios à regionalização" (IBGE, 1969) serve bem a esse propósito. Aqui, nessa amplíssima coletânea de cartogramas temáticos e propostas de espacialização no território brasileiro, os geógrafos do IBGE renunciam à condição da tarefa de propor uma Divisão Regional do Brasil (como aquele de 1942) e limitam-se à tarefa coadjuvante de oferecer subsídios aos economistas. O IBGE passa a coadjuvar o Ipea (Instituto de Pesquisas Econômicas Aplicadas).

Esse fato pode ser tomado como marco do declínio do papel dos geógrafos e da Geografia na Fundação IBGE. Os geógrafos, segundo o ritmo das aposentadorias, vão se tornando o geógrafo numa espécie em extinção, enquanto são substituídos por analistas de sistemas, sociólogos, economistas. Permanece um núcleo inexpressivo de remanescentes do extinto Projeto Radam-Brasil que, sob a rotulagem de "Recursos Naturais", está fadado ao desaparecimento.

Não desejo que esse exemplo seja tido como um remate de males de minha parte. O que pretendo extrair dele é a questão do papel ou da importância dos diferentes membros num dado conjunto de prática interdisciplinar. Haverá uma necessidade de que a constituição da equipe seja baseada no prestígio que alcançam as profissões junto ao poder?

Sobretudo se nos voltarmos para o caso especial da questão ambiental, não vejo necessidade de que uma equipe seja estruturada hierarquicamente à base de primeiros atores, coadjuvantes e figurantes, como nas artes cênicas. Pode até dar-se que, segundo a natureza e o grau de acuidade do problema, a proposta da montagem de uma equipe venha a ser dirigida por algum profissional vinculado à fonte do problema. Mas a pequena mas significativa experiência que tive em meus anos de militância de docência e pesqui$\mathrm{sa}^{6}$ leva-me a depor que o grau de importância, prestígio ou destaque do membro de uma equipe interdisciplinar não emana da profissão, mas da capacidade pessoal demonstrada pelo profissional no seu desempenho junto à equipe na condução das análises e soluções apontadas ao problema focalizado.

Postas essas considerações, creio que já é tempo de arrematar esta fala, fazendo um chamamento aos meus colegas geógrafos para uma reflexão importante, no sentido de volver um olhar ao passado para reavaliar os "princípios" que nos foram legados; refletir sobre a complexidade do presente e vislumbrar possibilidades futuras.

Sabemos que as características básicas de uma grande crise histórica, como aquele que atravessamos, seriam a revisão, desmonte-reconstrução dos conceitos de razão, conhecimento (episteme) para o que culminaria na emergência de um novo humanismo. Em relação ao problema epistemológico, além de uma nova visão sobre ciência e arte: a "nova aliança" (PRIGOGINE; STENGERS, 1979).

A Geografia, quando de seu embasamento e instituição científica, assentava-se sobretudo nessa condição cognitiva de um jogo de interações, conexões, já que a essência do fato geográfico torna o objeto fundamentalmente complexo pelo entrosamento do natural e do social. Tanto foi assim que essa harmonização sintônica de vários saberes para compreendermos os mundos em que vivemos revestiu a Geografia de créditos como veículo de educação. Seria flagrantemente paradoxal que, justo no momento histórico em que se clama por um conhecimento mais conjuntivo, a Geografia venha renunciar aquilo que deve ser o seu grande trunfo, a sua própria razão de ser.

E isso já está a caminho, posto que geógrafos das novas gerações estão procurando mergulhar nas fontes, nas raízes da fundamentação científica de Geografia. Um exemplo expressivo desse fato é a "revivescência" que, a partir dos anos noventa, vem sendo feita dos aspectos "culturais" da Geografia. ${ }^{7}$ Mas o fato mais notável é aquele da virada

6 Dentro das limitações de um regime de trabalho em tempo integral (e dedicação exclusiva) no Depto. de Geografia da FFLCH/USP, nas décadas de setenta e oitenta tive ocasiões de ampliar minhas experiências de campo em planejamento territorial prestando consultoria em equipes de Implantação Urbana, dirigidas por arquitetos urbanistas de São Paulo (Joaquim Guedes, em especial) e junto à Secretaria de Planejamento, Ciência e Tecnologia do Estado da Bahia (1975 a 1985). 7 Fato que pode ser batizado pela criação do Núcleo de Estudos e Pesquisas sobre Espaço e Cultura - Nepec na Universidade do Estado do Rio de Janeiro (Centro de Tecnologia e Ciências - Instituto de Geociências - Departamento de Geografia), em 1992. 
MONTEIRO, C. A. de F. Interdisciplinaridade, meio ambiente e desenvolvimento...

ocorrido pelo contraste entre o que se apregoava durante a dita revolução teorética quantitativa que abalou nossa Geografia nos anos setenta - relegar ao lixo o legado de Vidal de la Blache, por exemplo - e nessa virada de século. Agora, a obra de um dos fundadores da escola francesa de Geografia - exatamente Vidal de la Blache - está a merecer a atenção de nossos jovens geógrafos. ${ }^{8}$

É indiscutível que, no quadro da permanente e perpétua mutabilidade no tempo, ao longo do qual variam as condições de análise, e as ferramentas técnicas de traba- lho, aprimoram-se grandemente pondo em evidência fatos ainda não revelados. Mas ao lado da limitação de validade técnica há como que uma permanência, necessariamente readaptações de conceitos, de idéias, até mesmo de estratégias metodológicas propostas pelas grandes cabeças dos criadores da geografia-ciência.

Essa recuperação do conjuntivo, do conectado na Geografia certamente aprimorará não só a nossa capacidade de adiantar o conhecimento geográfico como nos habilitará a um melhor desempenho na prática da interdisciplinaridade.

\section{REFERÊNCIAS}

CERI - Centre for Educational Research and Innovation. Interdisciplinarity: Problems of Teaching and Research in Universities. In: SEMINAR ON INTERDISCIPLINARITY IN UNIVERSITIE, 1970, France. CERI, French Ministry of Education at the University of Nice, sponsored by OECD Organization for Economic Co-operation and Development. 319 p.: il.

DANTAS DA SILVA, Aldo Aloísio. Conexidade e geografia. Cronos - Revista do Programa de Pós-Graduação em Ciências Sociais da UFRN, Natal: UFRN, v. 3, n. 1, p. 11-25, jan./jun. 2002.

GOMES, Paulo Cesar da Costa. Milieu et Métaphysique: une interpretation de la pensée vidalienne. In: BERDOULAX, V.; SOUBEYRAN, O. (Orgs.). Milieu, Colonization et Development Durable. Paris: Harmattan, 2000.

JANTSCH, Erich. Towards Interdisciplinarity and Transdisciplinarity in Education and Innovation. In: CERI. Interdisciplinarity: Problems of Teaching and Research in Universities, 1970, p. 97-121.

JAPIASSU, Hamilton. A patologia do saber $e$ a interdisciplinaridade. São Paulo: Imago, 1976.

MAMIGONIAN, Armén. Geografia e a "formação social" como teoria e como método. In: SOUSA, M. A. A. de. (Org.).
O mundo cidadão, um cidadão do mundo. São Paulo: Hucitec, 1996. p. 198-200.

MONTEIRO, C. A. de Figueiredo. Derivações antropogênicas dos geossistemas terrestres no Brasil e alterações climáticas. In: SIMPÓSIO COMUNIDADE VEGETAL COMO UNIDADE BIOLÓGICA, TURÍSTICA E ECONÔMICA, 1978, São Paulo. Anais... São Paulo: ACIESP - Secretaria de Cultura, Ciência e Tecnologia do Estado de São Paulo, n. 15, p. 45-74. (Reeditado In: RA'EGA: o espaço geográfico em análise, Curitiba: UFPR, n. 5, ano 5, p. 193-206, 2001. Resgate de textos geográficos.

Os geossistemas como elementos de integração na síntese geográfica e fator de promoção interdisciplinar na compreensão do ambiente. Revista de Ciências Humanas, v. 14, n. 19, p. 67-101: Il. mar. 1995.

PRIGOGINE, Ilya; STENGERS, Isabelle. La Nouvelle Alliance-metamorphose de la science, 2. ed. Paris, Gallimard: Col. Foleo, Essais, 1986. 445 p.: Il.

ROCKENBACH, Denise; CALVENTE, Maria del Carmen H. Reflexões sobre a interdisciplinaridade. Informa, São Paulo: Órgão Oficial da AGB, p. 38, jan./jun. 1991.

8 Dentro das limitações do meu atual grau de informação sobre a produção geográfica no Brasil, chamo a atenção para as contribuições de Paulo César Gomes (UFRJ) e Aldo Aloísio Dantas da Silva (UFRN) sobre Vidal de la Blache. Vide referências bibliográficas. 